\title{
The Relationship between WTC Level and LLS Use among Turkish EFL Learners
}

\author{
Ali Merç \\ Anadolu University, Turkey \\ amerc@anadolu.edu.tr
}

\begin{abstract}
Recent investigations in the field of applied linguistics have tended to transfer psychological concepts into second language acquisition. Willingness to communicate, as a psychological concept, has been taken as a research topic in the field. On the other hand, language learning strategy use has been accepted as a notion affecting the success in second/foreign language learning. In this respect, this study investigates the relationship between the levels of Willingness to Communicate inside the Classroom (WTC) and Language Learning Strategy (LLS) use among Turkish university students. 80 first-year university students responded to two questionnaires: WTC questionnaire developed by McIntyre et al (2001) and the Strategy Inventory for Language Learning (SILL), version 5.1 by Oxford (1990). The results of the quantitative analyses, first, revealed that Turkish EFL learners were willing to communicate in the classroom in a range from half of the time to usually willing in both overall mean score and in separate components such as speaking, reading, writing, and comprehension. Second, the participants were found to be medium strategy users. Finally, correlation analyses showed that there was a significant positive correlation between these two concepts. In specific, certain aspects of the levels of WTC inside classroom matched with certain sub-components of the SILL. After the study, a number of recommendations for language learning and teaching as well as some implications for further research are provided.
\end{abstract}

Keywords: Willingness to Communicate, Language Learning Strategies, Language Learning, Language Teaching 


\section{Introduction}

Within language learning research area, certain factors were identified that affect the language learning process and especially, the learner. Ellis (1994) states that external factors such as social factors, input, and interaction; and internal factors such as language transfer, cognitive accounts, and language universals may be the factors having impacts on language learning. However, although these factors are necessary, they would not be sufficient to explain the language learning differences stemming from the learners' own personality and characters, namely affective factors (Hashimoto, 2002). Moreover, according to MacIntyre, Baker, Clement and Donovan (2002), the modern language teaching gives great emphasis on communication which is strongly correlated with individual learner differences in language learning. In the same respect, the goal of language learning is seen as promoting communication and understanding between the individual learners from different language and cultural backgrounds (Yashima, Zenuk-Nishide \& Shimizu, 2004).

The above considerations are related to a new concept that Strong (2001) identifies as the new effect of motivation on language learning: willingness to communicate (WTC). In order to comprehend what WTC means better, McCroskey and Richmond (1990a) will be essential to quote:

Although talk probably is a vital component in interpersonal communication and the development of interpersonal relationships in all cultures, people differ dramatically from one another in the degree to which they actually do talk. Some people talk very little, they tend to speak only when spoken to-and sometimes not even then. Others tend to verbalize almost constantly. Many people talk more in some contexts than in others, and most people talk more to some receivers than they do to others. This variability in talking behavior among people is alleged to be rooted in a personality variable, which we call "Willingness to Communicate"(p. 72). 
This quotation gives us a broad understanding of what WTC means as both a personality concern and as one of the individual differences among language learners. Although WTC is a communication research issue in which certain studies were conducted to clarify the differences among certain individuals and people of different cultures (Zakahi \& McCroskey, 1989; McCroskey \& Richmond, 1990b; Salinen-Kuparinen \& McCroskey, 1991), it has also been the research interest of second/foreign language learning scholars. Studies on this issue have focused on the influence of attitudes and affect on WTC and second language communication (Yashima, Zenuk-Nishide \& Shimizu 2004), correlations among WTC, communication apprehension, perceived competence, and integrative motivation (MacIntyre, Baker, Clément \& Donovan, 2003), the effects of sex and age on WTC (MacIntyre, Baker, Clément \& Donovan, 2002), the effects of motivation and WTC on reported L2 use (Hashimoto, 2002), the relationship between WTC inside and outside the classroom and language learning orientations (Zarrianabadi \& Abdi, 2011) the correlations among WTC inside and outside the classroom, social support, and language learning orientations (McIntyre, Baker, Clément \& Conrod, 2001; Merç, 2008), the correlations among WTC, language proficiency, and anxiety (Alemi, Daftarifard \& Pashmforoosh, 2011), and the relationship between WTC and action control (MacIntyre \& Doucette, 2010).

Another concept in second language learning, as one of the individual differences, is the use of language learning strategies (LLSs). LLSs can be defined as the specific steps that are taken by individual language learners to foster their own language learning (Yamamori, Isoda, Hiromori \& Oxford, 2003). According to Oxford (1990), language learners hold the notion of LLSs in order to find their ways for better and faster language learning.

In the recent literature on second language acquisition, there is little evidence on the relationship between the use of language learning strategies and affective factors influencing second language 
acquisition. However, knowledge of the relationship of LLS use and affective variables in language learning might provide language teachers with the idea about their students' specific actions in their processes of language learning and their satisfaction with their language classes (Yang, 1999). Therefore, this study aims to report a research that investigates the relationship between WTC inside the classroom and the use of LLSs.

\section{Review of Literature}

\section{Willingness to Communicate (WTC)}

"WTC is to a major degree situationally dependent. Nevertheless, individuals exhibit regular WTC tendencies across situations" (McCroskey \& Richmond, 1990b). Namely, where individuals are willing to communicate is difficult to determine. The communication research on WTC has been the work of over half century, and one very popular measurement has been the research material of the studies. The 20-item probability-estimate scale requests participants to express the percentage of probability for them to start the conversation in certain situations. This scale has quite a high content and predictive validity as well as reliability as McCroskey (1992) found out. Moreover, certain studies on WTC (Zakahi \& McCroskey, 1989; McCroskey \& Richmond, 1990a; McCroskey \& Richmond, 1990b; Sallinen-Kuparinen \& McCroskey, 1991) used this scale as the research tool.

Zakahi and McCroskey (1989) investigated whether high WTC individuals were more likely to participate in an 'out-of-class' communication study or not with 381 students in an introductory communication class. The results showed that high WTC students were more likely to participate in out-of-class communication study, were more likely to be scheduled before the study, and were more likely to participate after persistent efforts of the researcher than the low WTC subjects. The researchers suggest that most students are hesitant to take part in communication studies, that's 
why even high WTC students participated within the persistent efforts of the researcher. Moreover, Zakahi and McCroskey conclude that communication studies bear in mind the WTC level of the students for their studies.

Likewise, a study for the relationship between WTC and other individual differences comes from McCroskey and Richmond (1990a). In their descriptive study, McCroskey and Richmond claim that WTC and extroversion are strongly correlated. They also indicate, considering the research results, that the ones with high self-esteem might be more willing to communicate. However, they conclude that those correlations would be related to differences between individuals who participated in the studies and further studies are needed.

A similar study was conducted by Sallinen-Kuparinen et al (1991) to investigate the cross-cultural differences between Finnish and other populations in terms of communication orientations such as WTC, communication apprehension, introversion, and self-reported communication competence with 249 college students. The results put forward that Finnish students were less willing to communicate than the students from other countries. Also, differences between Finnish and other cultures appear in introversion. While they were found to be more introverted ones, the other variables including communication apprehension and self-reported communication competence did not show significant differences among cultures. Researchers conclude that differences and similarities are associated with cultural differences between Finnish and other populations.

In response to the connection between WTC as a popular communication research area and second language acquisition research, McIntyre et al (1998) suggested a pyramid called "Heuristic Model of Variables Influencing WTC". At the top of the pyramid, the L2 communication takes place just after completing the step of WTC stage, in other words, L2 learners start from the bottom of the pyramid, and are able to reach L2 communication at the top layer. By following the steps below, a 
language learner is supposed to achieve the level of communicative L2 use. The pyramid consists of six layers with situations in different contexts (p. 371):

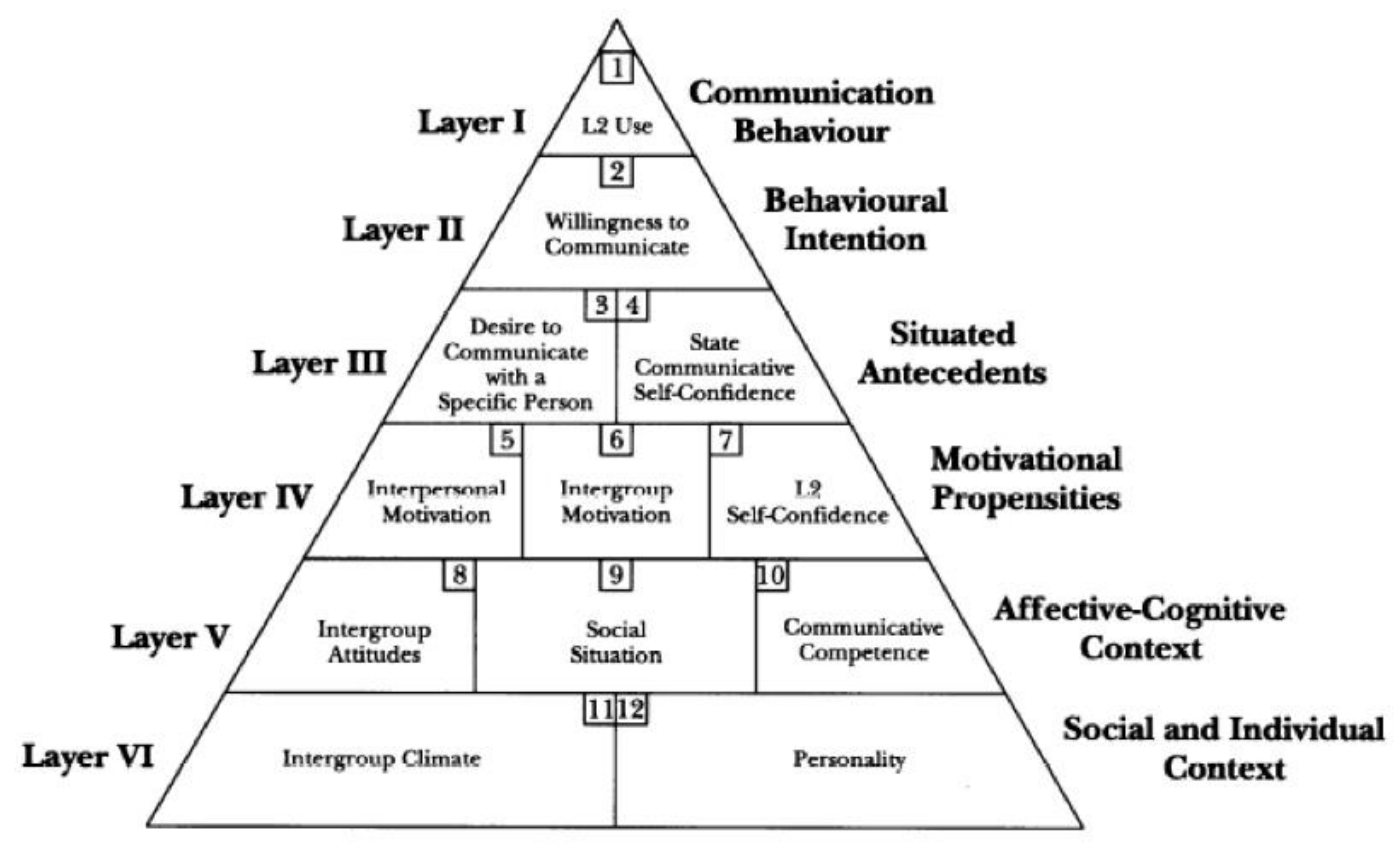

Figure 1. Heuristic Model of Variables Influencing WTC

Under the light of the pyramid above which integrate communication behavior and L2 learning, MacIntyre et al (2001) conducted a study to examine the correlations among WTC inside and outside the classroom, social support, and language learning orientations of immersion students in Quebec, Canada. Their study with 79 English-speaking students who have been learning French as a second language used a four-part questionnaire. The results showed that there were significant correlations between WTC inside and outside the classroom. Also, the researchers found that stronger orientations for language learning tended to be more highly related to WTC outside the classroom. Moreover, considering the role of social support in WTC, they found that immersion students had higher WTC inside than outside the classroom, but social support, especially from their peers, played a great role for WTC outside the classroom. Likewise, the social support of the 
friends was found to be highly related to traveling and making friendships with Francophones in terms of investigating the effect of social support on language orientations.

The role of WTC in second language acquisition and its relationship with variables influencing second language acquisition have been the research interests of certain scholars in the last few years. A handful of researchers investigated WTC as a variable in second language learning in different contexts such as the influence of attitudes and affect on WTC and second language communication (Yashima et al, 2004), correlations among WTC, communication apprehension, perceived competence, and integrative motivation (MacIntyre et al, 2003), the effects of sex and age on WTC (MacIntyre et al, 2002), the effects of motivation and WTC on reported L2 use (Hashimoto, 2002).

Hashimoto (2002) conducted a study to find out the effect of the two affective variables (motivation and WTC) on reported L2 use with 56 Japanese university students attending graduate and undergraduate courses in the University of Hawaii at Honolulu. The study used the WTC questionnaire to determine the WTC level of the students. The results of the study suggested that both motivation and the level of WTC affected the reported L2 communication frequency in the classrooms as the study hypothesized. Also, higher motivation was found to be positively correlated with higher perceived competence. The researcher discusses that L2 anxiety was the cause of low WTC, and perceived competence led to more L2 use in the classrooms. However, there was no significant correlation between WTC level and motivation as the indicators of high or low L2 use in the classrooms.

In a similar study, MacIntyre et al (2002) examined the effect of sex and age on WTC, anxiety, perceived competence, and L2 motivation among Junior High School French immersion students in the 7th, 8th, and 9th grades. 284 students (96 males and 188 females with a median age of 13 
years) participated in the study by answering the 20 -item WTC questionnaire to identify the WTC levels. The results of the study indicated that the correlates of L2 WTC can change as the students gain experience with the L2. For example, the researchers claimed that inexperienced language learners might be using their L1 self-confidence to support their WTC in the L2. The study also revealed results on gender differences in WTC levels. Girls in grade 9 had significantly higher level of WTC than boys in grade 9; grade 8 and grade 7 girls did not differ significantly from grade 8 and grade 7 boys. Furthermore, while boys did not differ in WTC level over three grades, grade 9 girls are higher in WTC than grade 7 girls.

In another study, MacIntyre et al (2003) investigated the differences between immersion and nonimmersion students in terms of WTC, communication apprehension, perceived competence, and frequency of communicating. 59 volunteer students ( 44 females, 15 males, mean age = 20,5 years) participated in the study by responding to the 20 item WTC questionnaire. The results of the study indicated a clear difference between immersion and non-immersion students in terms of WTC level. The full immersion led to a higher WTC level in the L2, and the findings suggested that L2 communication apprehension and L2 perceived competence were the two influences on WTC in the L2.

Furthermore, in a recent article, Yashima et al (2004) examined the influence of attitudes and affect on WTC and second language communication in two investigations. For the first investigation, 154 students (141 female and 13 male) were used. The participants answered a questionnaire designed by the researchers that includes attitudinal/motivational measures and the 20 -item WTC questionnaire. The results of the study showed that WTC was highly correlated with communication anxiety and perceived communication competence, and frequency of communication. In the second investigation, 60 Japanese high school students (17 boys and 43 
girls with 16,1 mean age) who participated in a year-long study program in the United States participated in the study. The participants responded to two questionnaires: one before departure, and one during the visit to the US. The findings of the second investigation confirmed the results of the first investigation, which suggests WTC was highly correlated with communication anxiety and perceived communication competence, and frequency of communication. Also, the study found that frequency of communication correlated with satisfaction in interpersonal relationships during the visit to the US.

In addition to these correlation studies, Cao (2011) and Peng (2012) analyzed WTC from an ecological perspective, whose work resulted in the proposed idea that students' behavior is influenced by the classroom context, and more noticeably, that "L2 WTC in the innermost systemthe classroom- seemed to be nurtured by, and thus fluctuate because of the interaction between the factors internal and external to individual learners, and inside and beyond the classroom walls" (p. 211).

\section{Language Learning Strategies (LLS)}

Language learning strategies have been studied widely in the last two decades in an attempt to identify the "specific actions taken by the learner to make learning easier, faster, more enjoyable, more self-directed, more effective, and more transferable to new situations" (Oxford, 1990: 8).

Early considerations about language learning strategies were basically on the specific actions that 'good' language learners take in the process of language learning (Stern, 1983). This consideration took second language acquisition researchers to a point where language learning strategies were defined and described systematically. First, Chamot (1987) examined the LLSs in three main branches: cognitive, metacognitive, and socio-affective strategies. Following this categorization, Oxford (1990) developed a detailed list of LLSs in her taxonomy (Table 1) which consists of two 
broad categories: direct strategies and indirect strategies. There are three main types of direct LLSs: memory, cognitive, and compensation strategies. Memory strategies, such as grouping or using imagery have a highly specific function: helping students store and retrieve new information. Cognitive strategies, such as summarizing or reasoning deductively enable learners to understand and produce new language by many different means. Compensation strategies, like guessing or using synonyms allow learners to use the language despite their often large gaps in knowledge. Oxford also describes three types of indirect LLSs: metacognitive, affective, and social strategies. Metacognitive strategies allow learners to control their own cognition that is to coordinate the learning process by using functions such as centering, arranging, planning, and evaluating. Affective strategies help to regulate emotions, motivations, and attitudes. Social strategies help students learn through interaction with others.

Table 1.

Language Learning Strategies (Oxford, 1990)

I. Memory Strategies

Direct Strategies
A. Creating mental images
B. Applying images and sounds
C. Reviewing well

II. Cognitive Strategies
A. Practicing
B. Receiving and sending messages
C. Analyzing and reasoning
D. Creating structure for input and output

III. Compensation Strategies

A. Guessing intelligently

B. Overcoming limitations in speaking and writing

I. Metacognitive Strategies

$$
\text { Indirect Strategies }
$$
A. Centering your learning
B. Arranging and planning your learning
C. Evaluating your learning
A. Lowering your anxiety
B. Encouraging yourself
C. Taking your emotional temperature

II. Affective Strategies

III. Social Strategies

A. Asking questions

B. Cooperating with others 
Most of the empirical studies on LLSs have focused on the frequency of use of LLSs by language learners and its relationship with different variables affecting second language acquisition. For example, gender has been a variable for a handful of researchers to explain LLS use in recent years (Ehrman \& Oxford, 1988; Green \& Oxford, 1995; Y1lmaz, 1996; Sheorey, 1999; Wharton, 2000). Also, the effect of proficiency level on LLS use was examined in certain studies (Oxford \& Nykos, 1989; Green \& Oxford, 1995; Y1lmaz, 1996; Bremner, 1999; Sheorey, 1999; Wharton, 2000). Moreover, the effect of cultural and educational background of language learners (Purdie \& Oliver, 1998; Sheorey, 1999) and large class size (LoCastro, 1994) on LLS use were examined in different educational contexts.

In addition to the studies reflecting the LLS use of language learners and its relationship between certain variables, the relationship between affective variables in language learning and LLS use has also been among the research interests (Yang 1999; Wakamoto, 2000; Wharton, 2000).

In a recent study, Yang (1999) investigated the correlation between second language learners' beliefs about language learning and their LLS use. 505 students (194 males and 311 females) responded to two questionnaires: one for determining LLS use, and one for determining the beliefs about language learning. Factor analysis identified four factors that constitute subjects' beliefs about language learning: a) self-efficacy and expectation about language learning, b) perceived value and nature of learning spoken English, c) beliefs about foreign language aptitude, and d) beliefs about formal structure studies. Factor analysis for the LLS questionnaire identified six strategies: a) functional practice strategies, b) cognitive-memory strategies, c) metacognitive strategies, d) formal oral-practice strategies, e) social strategies, and f) compensation strategies. The correlation analyses of the study suggested that language learners' self-efficacy beliefs about 
language learning were strongly related to their use of all types of LLSs. Also, learners' beliefs about the value and nature of learning spoken English were interrelated with their use of formal oral-practice strategies.

In another study, Wakamoto (2000) investigated the relationship between LLS use and extroversion/introversion as two personality factors. 222 Japanese junior college students majoring in English responded to two research tools: the MBTI (Myers-Briggs Type Indicator) to identify learners in terms of extroversion/introversion and the SILL (Strategy Inventory for Language Learning). The results of the study showed that extroversion was significantly correlated with the use of functional practice strategies and social-affective strategies. Also, some specific strategies used by participants were closely linked to extroversion such as asking for clarification or verification, reading for pleasure in English, and practicing English with other students.

In an earlier study, Oxford and Nykos (1989) investigated the relationship between degree of motivation and the use of LLSs with more than 1200 students. The participants were delivered the early version of Strategy Inventory for Language Learning and a background questionnaire to learn about self-perceptions of motivation. The findings of the study revealed that there was a strong relationship between motivation and use of LLSs. Researchers discussed that the more motivated students reported using learning strategies of all kinds more frequently than the less motivated students.

Following the Oxford and Nykos study in 1989, Wharton (2000) studied the relationship between overall LLS use and some background variables including motivation, self-rated proficiency, and language studied with 678 undergraduate students studying Japanese or French in Singapore. Participants were given an 80-item LLS questionnaire to identify their LLS use together with a 
background questionnaire to learn about their age, gender, mother tongue, major field of study, degree of motivation, languages regularly spoken, and proficiency self-ratings. The results indicated that degree of motivation had the most significant main effect on the use of LLSs. Researcher speculates that the more motivated the language learners are-no matter how proficient they are, the more LLSs they tend to use in the process of language learning.

\section{Statement of the Research Questions}

Within the past two decades in language learning research, there have been several attempts to describe WTC in L2 classrooms and the use of LLSs as variables in language learning. However, the relationship between the level of WTC inside the classroom and LLS use has not been defined yet. Therefore, this study aims to answer the following research questions considering the previous research on WTC level inside the classroom and LLS use of second language learners:

1. What is the level of WTC inside the classroom of Turkish EFL students in four language skills?

2. What is the frequency of LLS use among Turkish EFL students?

3. Is there a correlation between the level of WTC inside the classroom and LLS use?

\section{Methodology}

\section{Participants}

The participants in this study are 80 first-year university students (19 male and 61 female) from Anadolu University, Faculty of Education, English Language Department (AUELT). The ages of the participants range from 18 to 22 . The participants are all from Turkey, and they are all monolingual speakers of Turkish. The participants have been studying English for a number of years and they entered their department (AUELT) by answering questions on English as a Foreign Language. They were also given a proficiency test before they started their education; the ones 
who passed the exam were allowed to study in their department, and the ones who were not successful studied in prep class for a year. Therefore, the participants are both experienced language learners and have a high level of proficiency in EFL.

In their first year in ELT department, the students study four language skills (writing, reading, speaking, and listening) and grammar together with courses related to teaching (i.e. Introduction to Teaching Profession) and linguistics (i.e. Language Awareness). In these courses, the students are given explicit training neither on language learning strategy use nor on willingness to communicate inside the classroom. They are provided with certain strategies in their coursebooks such as reading strategies in reading coursebooks, and they are provided with the chance to participate in the classroom activities willingly by communicative activities (i.e. communicative grammar activities, tasks in speaking classes).

\section{Instruments}

In order to find out the level of WTC inside the classroom, this study aims to use a questionnaire developed by MacIntyre et al (2001), which consists of four sections. The questionnaire, originally, has the following four subsections:

a. Willingness to Communicate Inside the Classroom: There are 27 items that address students to measure their willingness to engage in classroom tasks and activities. The items include statements from four major L2 skill areas to identify the productive and receptive skill engagement. Students are asked to indicate their willingness to communicate on a scale from 1 to $5(1=$ almost never willing, $2=$ sometimes willing, $3=$ willing half of the time, 4=usually willing, 5=almost always willing) in each situation. 
b. Willingness to Communicate Outside the Classroom: there are 27 items that address students to measure their willingness to communicate outside the classroom. Students are asked to describe their willingness as mentioned in the previous subsection.

c. Orientations for Language Learning: Students are asked to indicate which particular reasons for learning a foreign language apply them on a scale from 1 to 6 (1=strongly agree, $2=$ moderately agree, $3=$ mildly agree, $4=$ mildly disagree, $5=$ moderately disagree, $6=$ strongly disagree). There are five determined orientations each with four items including “friendship, travel, knowledge, job-related, and school achievement".

d. Social Support: Students are asked to answer 'yes' or 'no' to six questions about who offered support for their learning a foreign language: mother, father, teacher, favorite sibling, best friend, and other friends.

Since this questionnaire had been designed for French immersion students in Canada and presented in English that is the native language of the participants, it was used in this study with certain modifications. First, the second (Willingness to Communicate Outside the Classroom), the third (Orientations for Language Learning), and the fourth (Social Support) subsections of the questionnaire was omitted since these subsections are not related to the aim of this study. Second, the remaining subsection of the questionnaire was translated into Turkish conducting the "backtranslation" method. For this reason, two bilingual professors from Anadolu University English Language Teaching Department were used. Third, the expression "French" was translated as “English" since this study uses English as the participants' L2.

This questionnaire, in its new version, asks for individuals' level of WTC inside the classroom in four skills; therefore, communication is not seen as oral communication only. What it means here is the two-sided oral and written communication types: reading and writing, and speaking and 
comprehension. Moreover, the 'comprehension' part in the questionnaire does not only measure willingness to listen and understand as a part of oral communication. Rather, it is also related with the comprehension of written stimuli as well as spoken. For example, in one of the items, it has a statement like "Fill out an application form". So 'comprehension' covers all kinds of comprehension, both oral and written.

In order to find out the LLS use of the participants, the Strategy Inventory for Language Learning (SILL), version 5.1 (Oxford, 1990) was used. The inventory is in the form of a Likert-scale questionnaire with 80 items. In this inventory, the respondents are supposed to respond to the statements on a scale ranging from 1 to $5(1=$ never or almost never true for me, $2=$ usually not true of me, $3=$ somewhat true of me, $4=$ usually true of me, $5=$ always or almost always true for me).

The SILL has six components (from A to F) each of which is an indicator of Oxford's (1990) classification of LLSs. Part A consists of statements about memory strategies such as grouping, using keywords, and using physical response or sensation. In Part B, there are statements related to cognitive strategies such as repeating, translating, and taking notes. Part C includes statements about compensation strategies like using linguistic clues, using mime or gesture, and coining words. Part D consists of statements about metacognitive strategies such as paying attention, organizing, and self-monitoring. In Part E, there are statements related to affective strategies like using laughter, taking risks widely, and using a checklist. Finally, Part F has statements about social strategies such as asking for correction, cooperating with others, and developing cultural understanding. The SILL has been the research instrument of several studies (LoCastro, 1994; Y1lmaz, 1996; Yang, 1999; Wakamoto, 2000; Wharton, 2000; Bull \& Ma, 2001) concerning the LLS use of language learners since it has quite a high reliability level (between .93 and .98 , respectively) (Green \& 
Oxford, 1995: 264). Also, Y1lmaz (1996) translated the SILL into Turkish for his study with Turkish EFL students. This study used the translated version of the SILL in order to have the ease of administration and to achieve the maximum accuracy in results as Y1lmaz (1996) suggested.

\section{Data Collection Procedure}

The modified version of the WTC questionnaire and the SILL were administered to the participants who were volunteers to take part in the study. They completed the two tests in their regular class hours under the supervision of their teacher. The tests required approximately 30 minutes per participant to complete. The students were also told not to write their names in order to make sure that the results would not be used to evaluate their performance, or as the part of the assessment of the courses they are taking.

\section{Data Analysis Procedure}

To answer the first research question "What is the level of WTC inside the classroom of Turkish EFL students", the frequencies of statements for the four language skills (writing, reading, speaking, and comprehension) were calculated and the mean scores were obtained to identify the level (high, average, and low) of WTC inside the classroom.

For the second research question "What is the frequency of LLS use among Turkish EFL students", the frequencies of each strategy for the six components of the SILL were calculated and the mean scores were obtained per participant. Therefore, the strategy use of each individual participant was found with the sub-categories in the SILL.

To answer the third research question "Is there a correlation between the level of WTC inside the classroom and LLS use", the Pearson correlation coefficients were calculated. 


\section{Results and Discussion}

The following section, first, presents the results of descriptive statistics on the level of WTC inside the classroom and frequencies of LLS use both for overall calculations and for each of the components in the scales in response to the first and second research questions which were "What is the level of WTC inside the classroom of Turkish EFL students in four language skills?" and "What is the frequency of LLS use among Turkish EFL students?" Second, the correlation coefficients are presented for the relationship between level of WTC inside the classroom and LLS use as an answer to the third research question, "Is there a correlation between the level of WTC inside the classroom and LLS use?"

\section{Level of Willingness to Communicate Inside the Classroom}

The first research question in this study was: "What is the level of WTC inside the classroom of Turkish EFL students in four language skills?" To answer this question, the 27 item likert-scale questionnaire with four sub-sections was administered to the participants. Table 2 presents the results of the descriptive analysis of the scale which includes the mean scores for each component from highest to lowest mean scores. The analysis of the WTC inside the classroom scale showed that the overall mean for WTC was 3.35 ( $3=$ Willing half of the time, $4=$ Usually willing). So, the participants were found to be somewhere between half willing to usually willing as the scale represents. The mean scores for the four components were also calculated separately to find out the level of WTC inside the classroom. The analysis revealed that willingness to read in class (not out loud) was the highest among four components (3.60). Comprehension in class was the second component that participants reported to be willing to communicate (3.50). Speaking in class as another component had the third place in terms of willingness (3.39) and the lowest mean among the components of the WTC scale was for willingness to write in class in English (3.06). 
Table 2.

Mean Scores for WTC Inside the Classroom

\begin{tabular}{lll}
\hline Components & N & Mean \\
\hline Reading & 80 & 3,6044 \\
Comprehension & 80 & 3,5075 \\
Speaking & 80 & 3,3870 \\
Writing & 80 & 3,0604 \\
\hline Overall & 80 & 3,3545 \\
1= Almost never willing \\
2= Sometimes willing \\
3= Willing half of the time \\
4= Usually willing \\
5= Almost always willing \\
\hline
\end{tabular}

As it is seen in Table 2, Turkish EFL learners are willing to communicate in the classroom in a range from half of the time to usually willing in both overall mean score and in separate components. In other words, they are neither unwilling nor high willing to communicate inside the classroom in terms of both overall willingness and willingness in four language skills. One noticeable finding on the level of WTC inside the classroom, the students are more willing for the two receptive language skills -reading and comprehension- and quite less willing for the productive skills -speaking and writing.

It can be predicted from the findings on WTC inside the classroom scale that communicating in L2 does not simply mean to take actions. When communication is taken as a two-sided activity in which there exist a sender and a recipient of a message, Turkish EFL learners can be thought as taking place on the recipient side of communication. Similarly, the results of the WTC scale can be explained by the assumption that WTC is quite closely related to the type of situation in which one may communicate (MacIntyre et al, 1998). As MacIntyre et al. (2001) suggests, learners can be observed in different situations more than simply asking them to answer already created situations in questionnaires in order to see their WTC levels. 
Another interpretation can be made about the participants' answers to WTC scale in terms of receptive and productive type of skills is that the students cannot find enough opportunities to produce language in the language classroom. Since they are more familiar with comprehension type of activities, they might be more willing to communicate in reading and comprehension skills. In contrast, they might be less experienced in the production of language in writing and speaking tasks together with the lack of opportunities to practice outside the classroom in a foreign language context, therefore, they may be less willing to initiate communication in speaking and writing skills.

\section{Language Learning Strategy Use}

The second research question in this study asked: "What is the frequency of LLS use among Turkish EFL students?" To answer this question, the 80 item likert-scale LLS inventory with six sub-sections was administered to the participants. Table 3 presents the results of the descriptive analysis of the inventory from highest to lowest mean scores for the components of the scale.

Table 3.

Mean Scores for LLS Use

\begin{tabular}{lcc}
\hline Components & N & Mean \\
\hline Overall & 80 & 3,2874 \\
Direct & 80 & 3,3313 \\
Indirect & 80 & 3,3211 \\
Compensation & 80 & 3,6385 \\
Metacognitive & 80 & 3,4183 \\
Social & 80 & 3,3631 \\
Cognitive & 80 & 3,2665 \\
Affective & 80 & 3,1821 \\
Memory & 80 & 3,0889 \\
\hline 1= Never or almost never true of me \\
2= Generally not true of me \\
3= Somewhat true of me \\
4= Generally true of me \\
5= Always or almost always true of me \\
\hline \multicolumn{3}{l}{} \\
\hline
\end{tabular}

The analysis indicated that the overall mean for the LLS use was 3,29 (3= somewhat true of me, $4=$ generally true of me). When the results are considered in terms of the direct vs. indirect 
strategies division, the mean scores for direct and indirect strategies were quite close to each other (3,33 for the direct and 3,32 for the indirect strategies, very close to the overall mean). Therefore, it might be better to present the results according to the mean scores for the six components of the inventory. When the analysis is considered for the six sub-sections of the inventory, compensation strategies were found to be the most frequently stated LLS type (3.64). Metacognitive strategies and social strategies are the second and third frequent strategies reported to be used $(3,42$ and 3,36 respectively). Among the six strategy types, cognitive strategies were ranked with a mean score of 3,27 ; and the affective strategies with 3,18. The least frequently used strategies were in the part of memory strategies $(3,09)$ among the six strategy types.

According to the results of the present study, Turkish learners of English are medium strategy users as Oxford (1990) suggests that averages between 2.5 to 3.4 refer to medium strategy use. In this respect, the findings on the use of LLSs seem completely consistent with Y1lmaz's (1996) study with Turkish EFL learners. First, all learners in both studies are medium strategy users in both overall use and in two main parts: direct and indirect strategy use. Second, compensation strategies are the most frequently reported strategy type by the learners followed by the metacognitive strategies. Social and cognitive strategies are the two types that follow the two most frequent strategy types. Again, in consistency with Y1lmaz (1996), affective and memory strategies are the two least frequently stated strategy types.

As the experienced language learners, the participants in this study can be counted as the ones who use LLSs less frequently than expected. According to Green and Oxford (1995), foreign language learners have a limited exposure to second language, which may cause them to use fewer LLSs in the environments where they are supposed to employ a number of strategies. Furthermore, Oxford 
(1990) is in favor of training L2 learners on the use of LLSs, and lack of strategy training can be a reason for learners to employ a limited range of LLSs in the process of learning a foreign language. The Relationship between Willingness to Communicate Inside the Classroom and Language

\section{Learning Strategy Use}

The third research question of the present study was: "Is there a correlation between the level of WTC inside the classroom and LLS use?" In order to answer this question, the Pearson correlations were run between the mean scores for WTC scale and LLS inventory. The analysis offered a positive relationship between these two variables $(\alpha=0.01, \mathrm{r}=.639)$. Further analysis included the investigation of the correlation among the components of the WTC inside the classroom scale and the parts of the LLS inventory. The results provided some insights into the relationship among those components with four types of relationship (see Table 4). 
Table 4.

Correlations among the components of WTC and LLS scales

\begin{tabular}{|c|c|c|c|c|c|c|c|c|c|c|c|c|}
\hline & 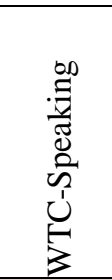 & 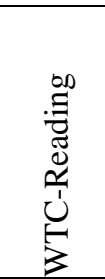 & 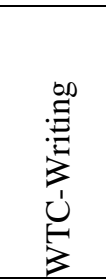 & 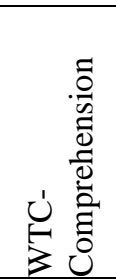 & $\begin{array}{l}\overline{7} \\
\overline{3} \\
0 \\
0 \\
0 \\
\vdots \\
3\end{array}$ & 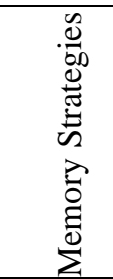 & 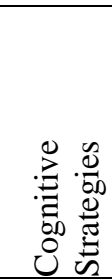 & 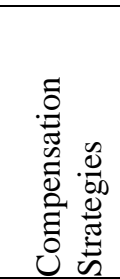 & 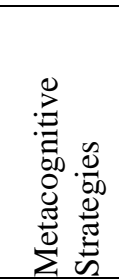 & 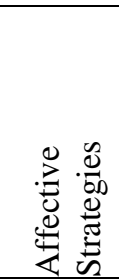 & 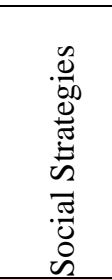 & 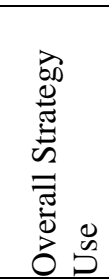 \\
\hline WTC-Speaking & 1 & & & & & & & & & & & \\
\hline WTC-Reading & $.546^{* *}$ & & & & & & & & & & & \\
\hline WTC-Writing & $.612^{* *}$ & $.680^{* * *}$ & & & & & & & & & & \\
\hline WTC-Comprehension & $.668^{* *}$ & $.699^{* * *}$ & $.733^{* * *}$ & 1 & & & & & & & & \\
\hline WTC- Overall & $.838^{* *}$ & $.815^{* *}$ & $.888^{* *}$ & $.875^{* *}$ & & & & & & & & \\
\hline Memory Strategies & $.425^{* *}$ & $.366^{* *}$ & $.417^{* * *}$ & $.486^{* * *}$. & $496^{* *}$ & 1 & & & & & & \\
\hline Cognitive Strategies & $.464^{* * *}$ & $.422^{* *}$ & $.402^{* *}$ & $.559^{* *}$ & $.518^{* *}$ & $.528^{* * *}$ & 1 & & & & & \\
\hline $\begin{array}{l}\text { Compensation } \\
\text { Strategies }\end{array}$ & $.449^{* * *}$ & $.471^{* *}$ & $.423^{* *}$ & $.477^{* *}$ & $.505^{* *}$ & $.265^{*}$ & $.477^{* * *}$ & 1 & & & & \\
\hline $\begin{array}{l}\text { Metacognitive } \\
\text { Strategies }\end{array}$ & $.556^{* * *}$ & $.473^{* *}$ & $.450^{* *}$ & $.611^{* *}$ & $.598^{* *}$ & $.549^{* *}$ & $.786^{* *}$ & $.598^{* *}$ & 1 & & & \\
\hline Affective Strategies & $.480^{* *}$ & $.419^{* *}$ & $.465^{* *}$ & $.451^{* * *}$ & $.518^{* *}$ & $.624^{* * *}$ & $.572^{* *}$ & $.408^{* *}$ & $.627^{* *}$ & 1 & & \\
\hline Social Strategies & $.578^{* *}$ & $.503^{* *}$ & $.476^{* *}$ & $.579^{* * *}$ & $.598^{* *}$ & $.523^{* * *}$ & $.659^{* *}$ & $.518^{* *}$ & $.691^{* * *}$ & $.598^{* *}$ & 1 & \\
\hline Overall Strategy Use & $.584^{* *}$ & $.511^{* *}$ & $.497^{* * *}$ & $.657^{* *}$ & $639^{* *}$ & $.746^{* *}$ & $.881^{* *}$ & $.592^{* *}$ & $.883^{* *}$ & $.737^{* * *}$ & $.821^{* *}$ & 1 \\
\hline
\end{tabular}

According to the correlation analyses, all components of both scales were significantly correlated with each other. In addition to the general link between the two variables, the relationship between willingness to read inside the classroom and the use of affective strategies can also be explained within the consideration that WTC has a trait like characteristic (MacIntyre et al., 1998). Also, according to MacIntyre et al (2001), learners are more willing to communicate in situations where they find themselves more confident. WTC in reading situations has the highest willingness level, so it is apparent that learners are employing affective strategies in correlation with willingness to 
read in their process of language learning. Furthrmore, the significant relationship between willingness to write inside the classroom and the use of compensation strategies can be explained within the understanding that students who were tending to use compensation strategies are found to be more willing to write inside the classroom. According to Oxford (1990), compensation strategies permit learners to produce written expression in the second/foreign language without complete knowledge. Therefore, some strategies (e.g. coining words, using a circumlocution or synonym, or selecting the topic) might help learners to write better in the L2 as well as making them more willing to take part in writing tasks in language classrooms. The link between willingness to comprehend and the use of memory strategies also lead to some interpretations. What the correlation suggests is students who use memory strategies are more willing for comprehension in classroom activities inside the classroom. As Oxford (1990) states, memory strategies help learners to store the information in the memory and retrieve it when they need to use, and enable them to enlarge their knowledge base. For example, semantic mapping, as a memory strategy, is valuable for improving comprehension of new expressions in L2 (Oxford, 1990).

In sum, although there have not been any studies directly examining the relationship between WTC inside the classroom and LLS use, the findings of the present work might provide some insights to the language learning research field. Especially the findings that correlate with Oxford's (1990) explanations of language learning strategies in relation with four language skills are worth discussing.

\section{Conclusion}

This study aimed to investigate the level of the willingness to communicate inside the classroom and language learning strategy use as well as the relationship between these two variables. The 
findings of the study provided both a better understanding of the WTC levels and LLS use of Turkish EFL students as well as the connections between WTC inside the classroom and LLS use. It found that WTC inside the classroom was correlated with LLS use. Considering the results of the study, second/foreign language instruction should attend to learners' strategy use, and it might expand the instruction for training learners on language learning strategies. This strategy training, also, should consider the level of learners' willingness to communicate inside the classroom. The more willing the learners are, the more strategies they will be using in their process of language learning in more appropriate ways with the self-confidence gained. For example, the reading tasks in language classrooms can be chosen from the ones that learners will be more willing to participate, which will lead students both to use a variety of strategies and to become better readers. By encouraging learners' willingness to communicate inside the classroom, teachers may enhance effective use of language learning strategies. Therefore, they will be able to contribute to learners' continuing motivation to learn second/foreign language.

Considering the assumption that success in learning an L2 might depend on the appropriate and frequent use of language learning strategies and a higher willingness to initiate L2 communication, the relationship between these two concepts should be examined by language learning/teaching researchers. Furthermore, the link between LLS use and other psychological factors such as motivation, attitude, etc. must be examined. The possible findings might shed light on the explanation of the various factors affecting second/foreign language learning.

This study has also some implications for further research in the field of second language learning. Since this study addresses only a small number of participants, the study can be replicated with larger groups in different settings. Whether the relationship is different with learners from different age group, whether it shows any gender differences, or whether type of instruction causes any 
distinctions can be examined. Furthermore, this study was a preliminary attempt to explain the relationship between LLS use and WTC. Some other studies can be conducted to examine the relationship of LLS use and WTC with other social, affective, and cognitive factors affecting successful L2 learning.

\section{References}

Alemi, M. Daftarifard, P. \& Pashmforoosh, R. (2011). The impact of language anxiety and language proficiency on WTC in EFL context. Cross-Cultural Communication, 7(3), 150166.

Bremner, S. (1999). Language learning strategies and language proficiency: investigating the relationship in Hong Kong. Canadian Modern Language Review 55: 490-515.

Bull, S. \& Ma, Y. (2001). Raising learner awareness of language learning strategies in situations of limited resources. Interactive Learning Environments, 9(2), 171-200.

Cao, Y. (2011). Investigating situational willingness to communicate within second language classrooms from an ecological perspective. System 39(4), 468-479.

Chamot, A. U. (1987). Learning Strategies of ESL Students. In Wenden, A. \& Rubin, J. (Eds.) 1987. Learner Strategies in Language Learning, pp. 71-83. Englewood Cliffs, NJ: Prentice Hall.

Ehrman, M. \& Oxford, R. (1989). Effects of sex differences, career choice, and psychological type on adult language learning strategies. The Modern Language Journal, 73, 1-13.

Ellis, R. (1994). The Study of Second Language Acquisition. Oxford University Press: Oxford.

Green, J. M. \& Oxford, R. (1995). A closer look at learning strategies, L2 proficiency, and gender. TESOL Quarterly, 29, 261-297. 
Hashimoto, Y. (2002). Motivation and willingness to communicate as predictors of reported L2 use: the Japanese ESL context. Second language Studies, 20 (2), 29-70.

LoCastro, V. (1994). Learning strategies and learning environments. TESOL Quarterly 28: 409-414.

McCroskey, J. C. (1992). Relaibility and validity of the willingness to communicate scale. Communication Quarterly, 40, 16-25.

McCroskey, J. C. \& Richmond, V. P. (1990a). Willingness to communicate: differing cultural perspectives. The Southern Communication Journal, 56, 72-77.

McCroskey, J. C. \& Richmond, V. P. (1990b). Willingness to communicate: a cognitive view. Journal of Social Behavior and personality, 5, 19-37.

MacIntyre, P.D., Baker, S. C., Clément, R. \& Conrod, S. (2001). Willingness to communicate, social support, and language-learning orientations of immersion students. Studies in Second Language Acquisition, 23, 369-388.

MacIntyre, P.D., Baker, S. C., Clément, R. \& Conrod, S. (2002). Sex and age effects on willingness to communicate, anxiety, perceived competence, and L2 motivation among junior high school French immersion students. Language Learning, 52(3), 537-564.

MacIntyre, P.D., Baker, S. C., Clément, R. \& Conrod, S. (2003). Talking in order to learn: willingness to communicate and intensive language programs. The Canadian Modern Language Review, 59(4), 589-607.

MacIntyre, P. D. \& Doucette, J. (2010). Willingness to communicate and action control. System, $38(2), 161-171$. 
Merç, A. (2008). Willingness to Communicate Inside the Classroom for Foreign Language Learners: A Study with Turkish Learners. Proceedings of the IASK International Conference: Teaching and Learning 2008, pp. 828-835. May, 26-28, Aveiro, Portugal.

Oxford, R. \& Nyikos, M. (1989). Variables affecting choice of language learning strategies by university students. The Modern Language Journal 73, 291-300.

Oxford, R. L. (1990). Language Learning Strategies: What Every Teacher Should Know. New York: Newbury House / Harper \&Row.

Peng, J. (2012). Towards an ecological understanding of willingness to communicate in EFL classrooms in China. System, 40, 203-213.

Purdie, N. \& Oliver, R. (1999). Language learning strategies used by bilingual school-aged children. System, 27, 375-388.

Sallinen-Kuparinen, A., McCroskey, J.C. \& Richmond, V. P. (1991). Willingness to communicate, communication apprehension, introversion, and self-reported communication competence: Finnish and American comparisons. Communication Research Reports, 8, 55-64.

Sheorey, R. (1999). An examination of language learning strategy use in the setting of an indigenized variety of English. System, 27, 173-190.

Stern, H. H. (1983). Fundamental Concepts of Language Teaching. Oxford: Oxford University Press.

Strong, G. (2001). Attitude and motivation in language learning: revisited. http://langue.hyper.chubu.ac.jp/jalt/pub/tlt/01/may/strong.html

Wakamato, N. (2000). Language learning strategy and personality variables: focusing on extroversion and introversion. IRAL: International Review of Applied Linguistics in Language Teaching, 38, 71-82. 
Wharton, G. (2000). Language learning strategy use of bilingual foreign language learners in Singapore. Language Learning, 50, 203-244.

Yamamori, K., Isoda, T., Hiromori, T., \& Oxford, R. L. (2003). Using Cluster Analysis to uncover learner differences in strategy use, will to learn, and achievement over time. IRAL, International Review of Applied Linguistics in Language Teaching, 41(4), 381-409.

Yang, N. (1999). The relationship between EFL learners' beliefs and learning strategy use. System, 27, 515-535.

Yashima, T., Zenuk-Nishide, L. \& Shimizu, K. (2004). The influence of attitudes and affect on willingness to communicate and second language communication. Language Learning, 54(1), 119-152.

Y1lmaz, V. (1996). Language learning strategies of Turkish EFL students and the effects of proficiency level and gender on strategy use. Eskisehir, Anadolu University: Unpublished MA Thesis.

Zakahi, W. R. \& McCroskey, J. C. (1989). Willingness to communicate: a potential confounding variable in communication research. Communication Reports, 2, 96-104.

Zarrianabadi, N \& Abdi, R. (2011). Willingness to communicate and language learning orientations in Iranian EFL context. International Education Studies, 4(4), 206-214. 